\title{
Destructive Operative Vaginal Delivery in a Tertiary Health Institution in Northwestern Nigeria : A Ten Year Review
}

\author{
Umar AG, Maiahu AI, Panti AA, Hassan M, Tunau K, Sulaiman B, Saidu AD
}

\begin{abstract}
A. BACKGROUND: Destructive operations are a group of obstetric procedures that are performed via the vaginal route by reducing the size of the head, shoulder girdle, or trunk of the dead foetus to allow vaginal deliveryto avert caesarean section and its complications.

B. AIMS AND OBJECTIVES:TO determining the incidence rate, indications, complications and outcome of destructive operations in UDUTH, Sokoto.

C. MATERIALS AND METHODS: This was a 10 year retrospective study of destructive operations performed at UDUTH. Sokoto, from ${ }^{\text {st }}$ January 2005 to $31^{\text {st }}$ December 2014. Information was extracted from patient's case files retrieved from the medical records department.

D.RESULTS: There were $\mathbf{2 8 , 4 2 2}$ deliveries during the period under review. The incidence of destructive operation was $0.31 \%$ and the mean age of the patients was $20 \pm 4.7$ years. Majority are in their $2^{\text {nd }}$ decades of life and they presented mainly as emergencies. The mean gestational age at presentation was $38.55 \pm 1.401$ weeks and the procedures were successful in all the cases. The most common procedure was craniotomy in 76/84 $(90.50 \%)$ and the main indication was prolonged and obstructed labour in 76/84 $(90.5 \%)$ of cases. The most frequent complication encountered was anaemia in 52/84 (61.9\%) of the patients and there were four cases of maternal deaths $(4.76 \%)$. E.CONCLUSION: Destructive operations still have a role in the management of obstructed labour particularly if the foetus is dead. However, the trend is on a decrease due to risk of complications that may lead to litigation.
\end{abstract}

Index Terms - Obstructed labour, Dead foetus, Destructive Operations.

\section{INTRODUCTION}

Destructive operations are a group of procedures that reduces the size of the dead foetus to allow vaginal delivery [1]-[3]. Prolonged labour is not seen in developed countries today, it is still occur in developing countries accounting for $8 \%$ of maternal deaths ${ }^{[4],[5)]}$

There are various methods of destructive operations that include; Craniotomy, Decapitation, Cleidotomy, Embryotomy and Craniocynthesis ${ }^{(5)}$ that had been described since $600 \mathrm{BC}{ }^{[6]}$.

Destructive operation is on a decline, thus major obstetric literatures rarely discuss it. Furthermore, the art is dying in Nigeria and obstetricians are resorting to caesarean

Umar AG, Usmanu Danfodiyo Univrsity Sokoto

Maiahu AI, Usmanu Danfodiyo Univrsity Teaching Hospital, Sokoto

Panti AA, Usmanu Danfodiyo Univrsity Sokoto

Hassan M, Usmanu Danfodiyo Univrsity Sokoto

Tunau K, Usmanu Danfodiyo Univrsity Sokoto

Sulaiman B, Usmanu Danfodiyo Univrsity Teaching Hospital, Sokoto

Saidu AD, Usmanu Danfodiyo Univrsity Teaching Hospital, Sokoto section $^{[7],[8]}$. There were rates of $0.26 \%^{[9]}$ and $0.21 \%{ }^{[10]}$ in India and Sudan.In Nigeria, $0.09 \%$ was reported in Ibadan ${ }^{[7]}$, $0.37 \%$ Enugu $^{[8]}$ and $0.5 \%$ in Zaria ${ }^{[11]}$. In Pondicherry and Haryana, Craniotomy was the most common procedure and Cleidotomy was least performed ${ }^{[12],}{ }^{[13]}$, while Cephalo-Pelvic disproportion was the most common indication. The complications included atonic postpartum haemorrhage, vaginal and perineal lacerations, puerperal sepsis, and urinary tract infection ${ }^{[13]}$. In Delhi, destructive operations had fewer complications with no maternal death, and short hospital stay while cesarean section had one maternal death, long hospital stay, need for blood transfusion, and frequent complications ${ }^{[14]}$. Destructive operations not only have a role in developing countries but are safer due to late presentation and aversion for Cesarean Section. Therefore, the aim of this study is to determine the incidence, indications, complications as well as outcome of destructive operations.

\section{METHODOLOGY}

This was a retrospective study on destructive operations carried out at the Usmanu Danfodiyo University Teaching Hospital, Sokoto (UDUTH) from $1^{\text {st }}$, January 2005 to $31^{\text {st }}$ ,December 2014.

Case files of parturients who had destructive operations over the period were retrieved from the medical records department and reviewed. The total number of deliveries during the study period was obtained and other relevant information on socio-demographic characteristics, booking status, parity, type of procedure, indications for the procedure, complications and maternal outcome following each method was obtained.

The information obtained was analysed using Statistical Software for Social Sciences (SPSS) version 20. Frequencies as well as mean were determined where necessary and the results were summarised in tables and charts.

Ethical clearance was obtained from the management of Usmanu Danfodiyo University Teaching Hospital, Sokoto.

\section{RESULTS}

The total number of deliveries during the study period was 28,422 and there were 89 destructive operations; giving an overall incidence of $0.31 \%$. The incidence ranged from 0.15 to 0.65 during the 10 years study period. It was highest in 2008 and lowest in 2013 through 2014 as depicted in table 1 below. Amongst the total number (89) of destructive operations during the study period, 84 (94\%) case files were retrieved and reviewed. Out of 84 files, 69(82.14\%) had full informations documented. 
Table 1: Destructive operation rates during the study period (TOTAL $=84)$

\begin{tabular}{ccc} 
Year & Total deliveries & $\begin{array}{c}\text { Destructive } \\
\text { operations } \\
\text { n(\%) }\end{array}$ \\
\hline 2005 & 2013 & $13(0.65 \%)$ \\
2006 & 2465 & $11(0.45 \%)$ \\
2007 & 2588 & $9(0.35 \%)$ \\
2008 & 3191 & $14(0.44 \%)$ \\
2009 & 3032 & $9(0.30 \%)$ \\
2010 & 2978 & $7(0.24 \%)$ \\
2011 & 3311 & $5(0.15 \%)$ \\
2012 & 3267 & $6(0.18 \%)$ \\
2013 & 3391 & $5(0.15 \%)$ \\
& 2186 & $5(0.29 \%)$ \\
\hline
\end{tabular}

The mean age of the patients that had destructive operative procedure was $20 \pm 4.7$, with the age

range being 16 to 45 years. Majority of the cases were in the age group of 19 years and below and $81 \%$ were Primigravidae. The patients were mostly of low socioeconomic class and had non-formal education. This is depicted in table 2 below.

Table 2. Socio-demographic characteristics of parturients.

Characteristic

n $\%$

Age

19 years and below 45

20 to 24 years

25 to 29 years

30 to 34 years

35 years and above

$\%$

53.6
27.4
9.5
8.3
1.2

27.4

9.5

8.3

1.2
Ethnicity

$\begin{array}{lll}\text { Hausa/Fulani } & 80 & 95.2\end{array}$

$\begin{array}{lll}\text { Yoruba } & 3 & 3.6\end{array}$

Igbo $\quad 0 \quad 0$

$\begin{array}{lll}\text { Others } & 1 & 1.2\end{array}$

\begin{tabular}{lll} 
Occupation & & \\
Employed & 0 & 0 \\
Unemployed & & 100 \\
& & \\
& & \\
Booking status & & \\
Booked & 3 & 3.6 \\
Unbooked & 81 & 96.4 \\
& & \\
& & \\
& & \\
Parity & & 81.0 \\
Primigravida & & 10.7 \\
2 to 4 & 68 & 8.3 \\
5 and above & 9 & \\
& 7 & \\
\hline
\end{tabular}

The result also showed that, the procedures were mainly carried out on the unbooked cases which accounted for $96.43 \%$ ), with only $3(3.57 \%)$ in booked cases who laboured at home and presented with obstruction as shown in figure1.The mean gestational age at presentation in this study was $38.55 \pm 1.401$ and the minimum gestational age was 34 weeks while the maximum was 42 weeks.

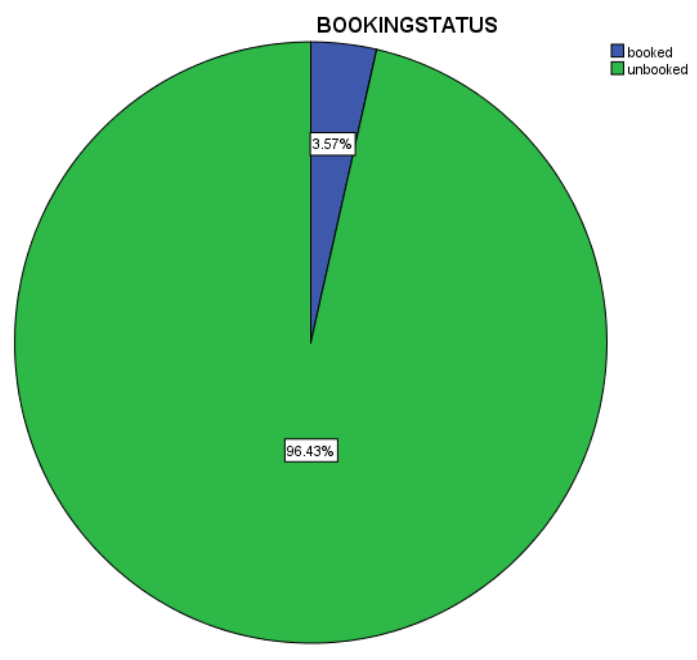

Figure 1: Booking status of the patients. 
Amongst the total number of operations performed during the study period, Craniotomy accounted for $90.48 \%(n=76)$, Ebryotomy $-2.38 \% \quad(n=2)$, while Decapitation and Craniocentesis accounted for $3.57 \%(n=3)$ each. This is shown in figure 2.

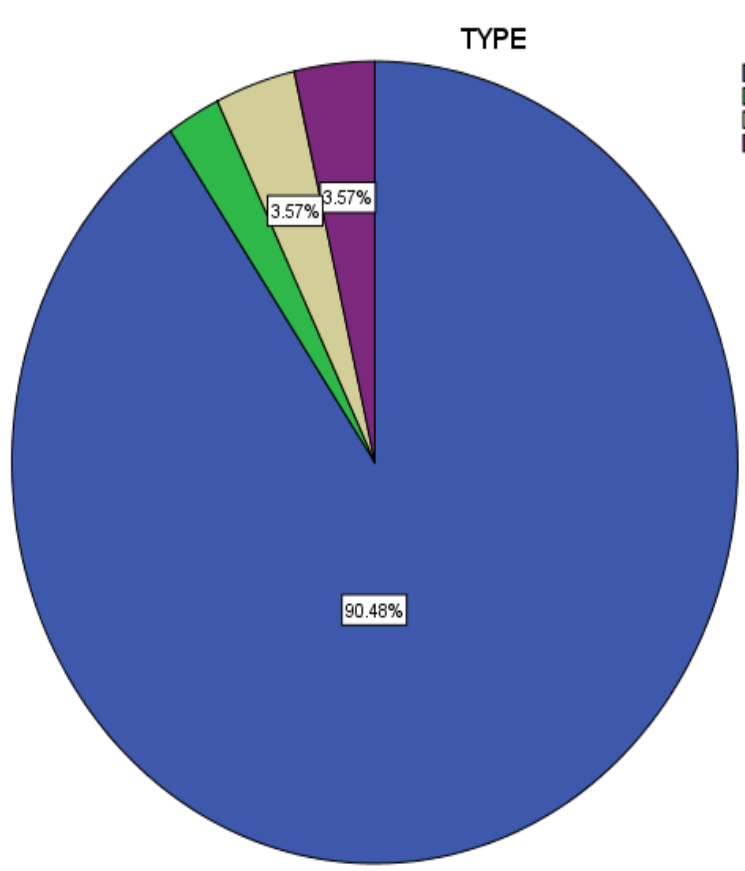

Figure 2: Type of destructive operation.

The most common indication for destructive operations was prolonged obstructed labour due to Cephalo-Pelvic disproportion in $76(89.58 \%)$ of cases, then hand prolapse in $5(8.34 \%)$ cases. The procedure was also carried out for the after coming head of the breach in $3(2.08 \%)$ cases among which one was a hydrocephalic baby. The distribution of the various indications for destructive operations is shown in figure 3 .

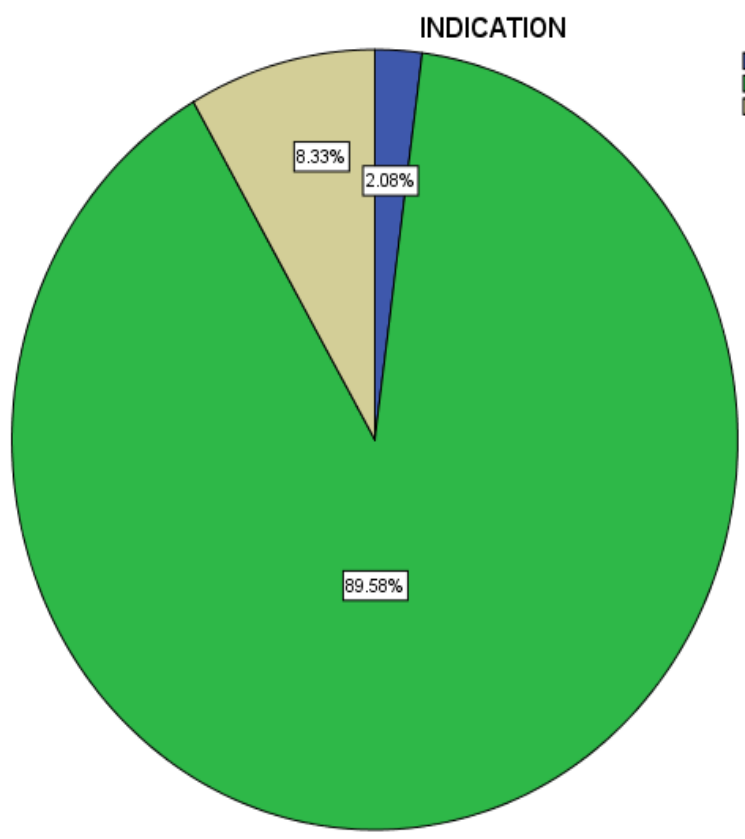

Figure 3: Indications for destructive operations.

The maternal complications encountered following destructive operations in this study are as shown in figure 3. The procedures were associated with varying degrees of complications and these commonly include anaemia, puerperal sepsis, fistulae and obstetric palsy. The most common complication observed in this study was anaemia which accounted for $61.9 \%$ of cases $(n=52)$. This was followed by sepsis which accounted for $47.6 \%(n=40)$ and Vesico-vaginal fistula in $28.6 \%(\mathrm{n}=12)$. RVF occurred in $2.38 \%(\mathrm{n}=2)$ and Four; $4.76 \%$ out them died postpartum (n ICRANIOTOM $F$ 4).The remaining, $13.09 \%(\mathrm{n}=11)$ had no obvious GEMBRYOTOMY

CRANIOCENTESISIt is however, noteworthy that significant number, $40.48 \%$ $(\mathrm{n}=34)$ of the patients had multiple complications. The above complications are as shown in figure 4 below.

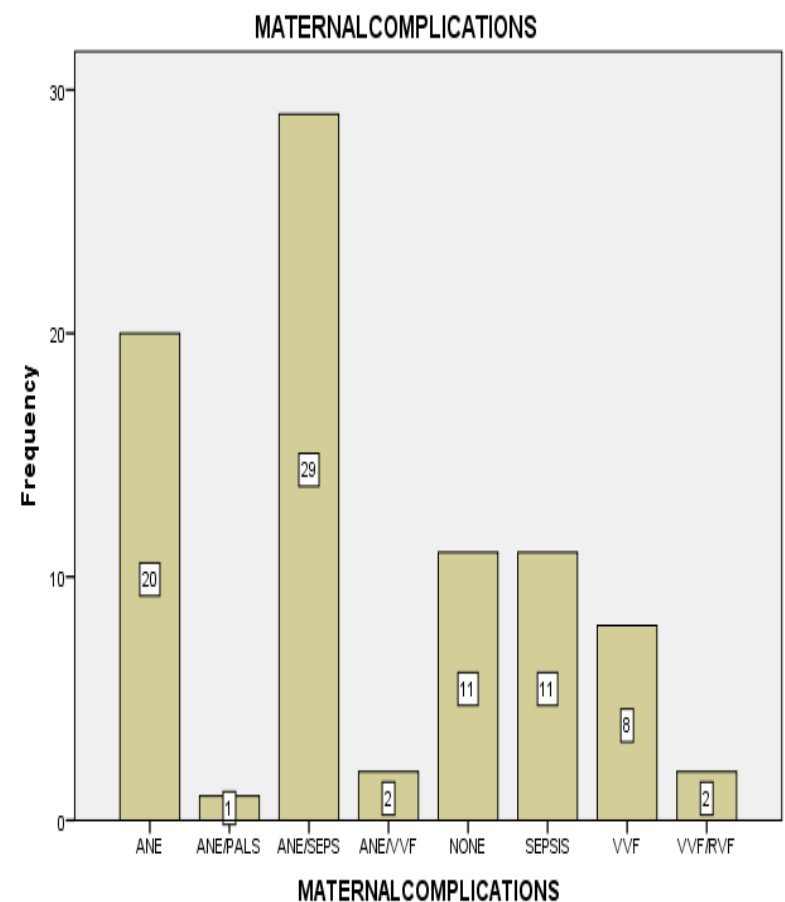

Figure 4: Maternal complications observed in destructive operations.

Key Words: ANE (anaemia), PALS (obstetric palsy), SEPS (sepsis), VVF (vesico-vaginal fistula), RVF (recto-vaginal fistula).

\section{$\mathrm{v}$ DISCUSSION}

The incidence of destructive operations found in this study was $0.31 \%$ which is similarly low as that observed in most studies, local and inter-national inclusive. It is also lower than that reported in some states in Nigeria like Zaria which was $0.5 \%^{[11]}$. This may be attributed to under utilisation of the procedures in the study area, probably due to lack of expertise to conduct such procedures, fear of complications that may arise as well as socio-cultural and religious objection of the procedure(s).

Destructive operations were carried out more on the younger age group mostly in their $2^{\text {nd }}$ decades of life and also more on primigravida who were in that age bracket. This may imply that primigravida are more likely to have prolonged obstructed labour and may require assistance to expedite delivery as a result of underdeveloped pelvis. Similar finding was also reported in some centres in northern Nigeria[15]. 


\section{Destructive Operative Vaginal Delivery in a Tertiary Health Institution in Northwestern Nigeria : A Ten Year Review}

Majority of the populace in the study area were Hausa and Muslims which may explain why most of the cases of destructive operations were in that ethnic group.

Inadequate monitoring of labour and lack of prompt interventions that frequently lead to prolonged and obstructed labour may explain why destructive operations were carried out more on unbooked patients than those who were booked. This is in conformity with the findings in Ibadan ${ }^{[7]}$. The study found that most of the cases of destructive operations had one form of complication or the other may not necessarily imply that the procedures are the causes of such complications but rather may be due to the inherent risks of the prolonged obstructed labour which the cases had. This is also in support of the Kolkata, Indian study. ${ }^{[10]}$ An example is the complication of anaemia that might have preceded the procedure. However, haemorrhage is a recognised complication.

It has been well documented that destructive operations are done for maternal benefits with the aim of avoiding the hazardous risks associated with caesarean section [12]-[14]. The indications for destructive operations in this study do not differ from those documented in previous studies (4],[7]-[10], [12]-[14] and Prolonged obstructed labour due to Cephalo-Pelvic disproportion with dead foetus was found to be the most common indication for these procedures which is similar to findings in previous studies ${ }^{[7], 1[1]}$

The procedures were carried out mainly on emergency basis and they were all successful with no case requiring caesarean section or laparotomy. There was also no statistically significant difference in the outcomes of the procedures.

However, there were four cases of maternal deaths among the cases which were primarily managed for eclampsia. This was also the case in previous studies $\left[{ }^{10]}\right.$. However, the exact causes were difficult to ascertain because of absence of post mortem examination.

\section{CONCLUSION AND RECOMMENDATION}

This study had identified that, the rate of destructive operations is similarly low as that obtained in most centres in Nigeria and the world at large. Most cases had one form of complication or the other; however, there was no statistically significant difference in complications observed between the various procedures. Although, destructive operative procedures are on the decline in modern obstetric practice, they however have role to play in the developing world. It is thus strongly recommended that obstetricians practicing in this part of the word acquire expertise in these procedures and conduct them safely whenever indicated.

\section{REFERENCES}

[1] Dutta DC. Operative obstetrics. In: Dutta DC, Konar H. (Eds) Textbook of obstetrics. 7th edition. New central book agency $(\mathrm{P})$ ltd, London. 2011: 563-98.

[2] Bikash S, Gupta S, Lomi C, Bipindra K. Foetal craniotomy: J Nepal Med Assoc 2014; 52(194): 810-12.

[3] Babatola B, Badejoko OO, Olumide A, Akinyemi A. Decompressive craniotomy in the management of entrapment of after coming head of breech with intrapartum foetal death in a rural centre; A case report: Tropical journal of Obstet and Gynae 2014; 31(1): 114-17.

[4] Islam JA, Ara G, Chaudhuri FR. Risk factors and outcome of obstructed labour at a tertiary care Hospital. J Shaheed Suhrawardy Med Coll, 2012; 4(2): 43-6.

[5] Orhue AA. Problems of labour. In: Akin Agboola. (Ed). Textbook of Obstetrics and Gynacology for medical students. 2nd edition. Heinemann educational books (Nigeria) PLC. 2006: 442-71.

[6] Obed SA. Obstructed labour. In: Kwawukume EY, Ekele BA, Danso KA, Emuveyan EE. (Eds). Comprehensive Obstetrics for the Tropics. 2nd edition. Ashante and Hitscher printing press limited, Ghana. 2014: 106-13.

[7] Konje JC, Obisesan KA, Ladipo OA. Obstructed labor in Ibadan. Int J Gynaecol Obstet.1992; (39): 17-21.

[8] Ezugwu FO, Anya SE,Nah HE, Okaro JM. Are Destructive Operations Still Relevant to Obstetric Practice in Developing Countries? Trop J Obst Gynaecol. 2002; 1: 90- 92.

[9] Sikka P, Chopra S, Kaipdev A, Jain V, Dhaliwal. Destructive Operations - a vanishishing art in modern obstetrics: 25 year experience at a tertiary care center in India: Arch Gynaecol Obstet. 2011;5: 929-933.

[10] Chakraborty PS,Das HS,Kalsar PK, Bose A. Role of Destructive Operations in Modern Day Obstetrics : J Ind Med Ass. 2001; 99:248-51

[11] Adaji, SE, Shittu, SO, Sule, ST. Operative vaginal deliveries in Zaria, Nigeria: Ann Afr Med.2009;(8) :95-9.

[12] Singhal SR. Chaudhary P, Sangwan K et al. De-structive operations in modern obstetrics.:Arch Gynecol Obstet 2005; (273): 107-9.

[13] Adhikari S, Dasgupta M, Sanghmita M. Management of obstructed labor; a retrospective study: J Obstet Gynecol India 2005; (55): 48-51.

[14] Gupta U, Chitra R. Destructive operations still have a place in developing countries. Int J Gynaecol Obstet 1994; (44): 15-9 